ARTICLE

\title{
Eliminating the capsule-like layer to promote glucose uptake for hyaluronan production by engineered Corynebacterium glutamicum
}

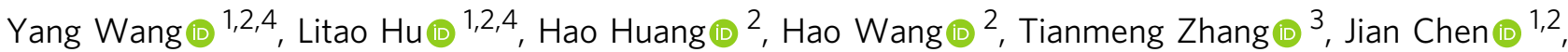 \\ Guocheng Du (i) ${ }^{1,2} \&$ Zhen Kang (1) ${ }^{1,2 \times}$
}

Hyaluronan is widely used in cosmetics and pharmaceutics. Development of robust and safe cell factories and cultivation approaches to efficiently produce hyaluronan is of many interests. Here, we describe the metabolic engineering of Corynebacterium glutamicum and application of a fermentation strategy to manufacture hyaluronan with different molecular weights. C. glutamicum is engineered by combinatorial overexpression of type I hyaluronan synthase, enzymes of intermediate metabolic pathways and attenuation of extracellular polysaccharide biosynthesis. The engineered strain produces $34.2 \mathrm{~g} \mathrm{~L}^{-1}$ hyaluronan in fedbatch cultures. We find secreted hyaluronan encapsulates $C$. glutamicum, changes its cell morphology and inhibits metabolism. Disruption of the encapsulation with leech hyaluronidase restores metabolism and leads to hyper hyaluronan productions of $74.1 \mathrm{~g} \mathrm{~L}^{-1}$. Meanwhile, the molecular weight of hyaluronan is also highly tunable. These results demonstrate combinatorial optimization of cell factories and the extracellular environment is efficacious and likely applicable for the production of other biopolymers.

\footnotetext{
${ }^{1}$ The Key Laboratory of Carbohydrate Chemistry and Biotechnology, Ministry of Education, Jiangnan University, 214122 Wuxi, China. ${ }^{2}$ The Key Laboratory of Industrial Biotechnology, Ministry of Education, School of Biotechnology, Jiangnan University, 214122 Wuxi, China. ${ }^{3}$ Bloomage Biotechnology CO, LTD, 250000 Jinan, China. ${ }^{4}$ These authors contributed equally: Yang Wang, Litao Hu. ${ }^{凶}$ email: zkang@jiangnan.edu.cn
} 
yaluronan (hyaluronic acid or HA) is a negatively charged, non-sulfated glycosaminoglycan comprising repeating uridine diphosphate glucuronate (UDP-GlcA) and uridine diphosphate $\mathrm{N}$-acetylglucosamine (UDP-GlcNAc) disaccharide units. It is a natural substance in vertebrates and mainly found in the eyes, joints and skin, where it absorbs large amounts of water for joint lubrication ${ }^{1}$, cell coating or repair of damaged skin tissue ${ }^{2}$. In addition to vertebrates, some pathogenic microorganisms, such as group A Streptococcus ${ }^{3}$ and Pasteurella multocida type A strains ${ }^{4}$, produce HA as the major component of their capsules for protection against exterior damage. Due to its biocompatibility, hygroscopicity and non-immunogenicity, HA and its derivatives are important to the cosmetics, pharmaceutical, biomedical, and food industries ${ }^{5-8}$.

Currently, commercial production of HA is mainly dependent on fermentation of group A Streptococcus ${ }^{9}$; however, high risk of pathogenicity to livestock and contamination by exotoxins in the HA product hinder its broader application. The development of metabolic engineering allows the engineering of non-pathogenic Escherichia coli strains for heterologous HA production ${ }^{10,11}$. To further eliminate potential safety concerns, many generally recognized as safe (GRAS) strains, such as Bacillus subtilis ${ }^{12-16}$, Lactococcus lactis ${ }^{17-20}$, Corynebacterium glutamicum ${ }^{21,22}$, and Pichia pastoris ${ }^{23}$, have been engineered as alternative producers of HA. Additionally, cell-free systems have been exploited to produce HA at specific molecular weight $(\mathrm{MW})^{24,25}$. Various strategies have been adopted to construct these HA producers, with selection of HA synthases and host strains representing the most critical step, as variations in HA synthase sequence, structural conformation $^{26}$, or host cell metabolic capacities make differences in HA yield or MW. HA synthase activities have been improved by protein engineering 24,27 or modification of the microenvironment of the enzymatic reaction, including the membrane lipid composition ${ }^{28}$. Moreover, metabolic engineering strategies such as overexpressing enzymes of intermediate metabolic pathways (e.g., UDP-glucose 6-dehydrogenase or glucosamine-1phosphate $\mathrm{N}$-acetyltransferase) or blocking the synthesis of unwanted metabolites (e.g., L-lactate) were adopted to drive the generation of intermediate metabolites required for $\mathrm{HA}$ synthesis $^{29,30}$.

In view of the GRAS status and metabolic capacity, C. glutamicum as the Gram-positive model organism has been engineered as an HA producer. In 2014, Hoffmann et al. ${ }^{21}$ first constructed the HA biosynthetic pathway by expressing Streptococcus equi subsp. zooepidemicus HA synthase (seHasA) in C. glutamicum. The engineered strain produced $1.2 \mathrm{~g} \mathrm{~L}^{-1}$ of HA. In 2016, Cheng et al. ${ }^{31}$ co-expressed the codon-optimized Streptococcus dysgalactiae subsp. equisimilis ssehas A gene along with endogenous $u g d A$ in C. glutamicum to produce $8.3 \mathrm{~g} \mathrm{~L}^{-1} \mathrm{HA}$ in fed-batch cultivation. Additionally, deletion of $l d h$, encoding lactate dehydrogenase, increased HA production to $21.6 \mathrm{~g} \mathrm{~L}^{-1}$ in fed-batch culture $^{29}$. A follow-up study enhanced the HA yield to $28.7 \mathrm{~g} \mathrm{~L}^{-1}$ by attenuating the glycolysis pathway, pentose phosphate pathway and the dehydrogenation of pyruvate ${ }^{22}$.

In the present study, we engineer C. glutamicum for high-yield HA production by selecting the most productive HA synthase, overexpressing enzymes of the intermediate pathways to convert glucose into the HA building blocks UDP-GlcA and UDPGlcNAc and decreasing endogenous extracellular polysaccharide biosynthesis. The engineered strain produces $34.2 \mathrm{~g} \mathrm{~L}^{-1} \mathrm{HA}$ in fed-batch cultures. Our analysis of cell morphology reveals that the secreted HA forms an HA capsule-like layer, which is subsequently found to restrict nutrient uptake and inhibit HA synthesis. To relieve this inhibition effect, we supplement leech hyaluronidase (LHYal, hydrolase $)^{32}$ to the fed-batch culture to disrupt cell encapsulation and decrease broth viscosity. This strategy significantly promotes glucose uptake and HA production.

\section{Results}

Construction of HA-producing C. glutamicum strains. HA synthase polymerizes HA chains using two building blocks: UDP-GlcA and UDP-GlcNAc (Fig. 1a). Two types of bacterial HA synthases have been identified: type I synthase is a bifunctional enzyme that polymerizes the HA chain, as well as transfers HA across the cell membrane ${ }^{33-35}$ (Supplementary Fig. 1); and type II HA synthase, found only in P. multocida ${ }^{36}$, is a cytosolic glycosyltransferase with high affinity to the cytoplasmic membrane (Supplementary Fig. 1). Here, HA synthases from $P$. multocida (pmHasA), S. pyogenes (spHasA), S. uberis (suHasA), and S. equi subsp. zooepidemicus HasA (seHasA) were selected and overexpressed individually in the host strain C. glutamicum ATCC 13032. Comparatively, spHasA generated the highest HA titer $\left(1.5 \mathrm{~g} \mathrm{~L}^{-1}\right)$ in shake-flask cultivation, which was 10 -fold and 7 -fold higher than that of seHasA and pmHasA, respectively (Fig. 1b). Almost no HA was synthesized by suHasA (Fig. 1b). Protein alignment showed seHasA ${ }^{21}$ and sseHasA $22,29,31$ share the same protein sequence. In comparison, there is $72 \%$ sequence identity between seHasA and spHasA and $71 \%$ sequence identity between suHasA and spHasA (Supplementary Fig. 2a). Western Blot demonstrated suHasA expressed very poorly in C. glutamicum while the expression levels of spHasA and seHasA are similar (Supplementary Fig. 2b). To further explore the reason of the distinct $\mathrm{HA}$ synthesis capabilities between seHasA and spHasA, we replaced the most dissimilar region of seHasA from spHasA, the first transmembrane helix Leu7-Val25 of seHasA with the corresponding transmembrane helix Thr7-Met25 of spHasA ${ }^{35}$ to generate seHasA Thr7-Met25. The mutant seHasA ${ }^{\text {Thr7-Met25 }}$ was expressed to the same level of the wild-type seHasA in C. glutamicum (Supplementary Fig. 2b). However, seHasA ${ }^{\text {Thr7-Met25 }}$ produced much higher amount of HA $\left(0.87 \mathrm{~g} \mathrm{~L}^{-1}\right.$, Supplementary Fig. 2c), suggesting the first tranmembrane helix of type I HA synthase should play critical roles in regulating HA synthesis.

After determining spHasA as the best performing HA synthase, all genes encoding enzymes related to intermediate metabolitesynthesis pathways, including galU, ugdA, $g \operatorname{lm} S, g \operatorname{lm} M$, and $g \operatorname{lm} U$, from five species (C. glutamicum ATCC13032, cg; B. subtilis 168, bs; S. equi subsp. zooepidemicus WSH-24, se; Pseudomonas putida KT2440, pt; and E. coli MG1655, ec) were selected and individually overexpressed to examine their contributions to HA formation. In particular, $u g d A$ genes (also known as $k f i D$ ) found in the heparosan-biosynthesis genome island of E. coli O10:K5:H4 ATCC 23506 (eco) and E. coli Nissle 1917 (ecn) (Supplementary Fig. 3) were investigated.

We found that UDP-glucose 6-dehydrogenase (UgdA) from different species exhibited different abilities to promote HA biosynthesis ( $4.5 \mathrm{~g} \mathrm{~L}^{-1}$, Fig. 1c). Endogenous UgdA encoded by cgugdA2 in C. glutamicum showed the best performance in enhancing $\mathrm{HA}$ biosynthesis as compared with GalU from S. equi subsp. zooepidemicus, GlmS, GlmM from P. putida and GlmU from B. subtilis, which showed similar capabilities at stimulating HA biosynthesis (around $2 \mathrm{~g} \mathrm{~L}^{-1}$ ) (Fig. $1 \mathrm{~d}$ and Supplementary Fig. $4 \mathrm{a}-\mathrm{c}$ ). Therefore, we overexpressed cgugdA2 along with $S$. equi subsp. zooepidemicus galU2 (segalU2), P. putida glmS (ptglmS) and $\operatorname{glm} M(p \operatorname{tg} \operatorname{lm} M)$ and B. subtilis $g \operatorname{lm} U(b \operatorname{sg} \operatorname{lm} U)$, respectively, finding that co-overexpression of cgugdA2 with ptglmS or ptglmM improved HA production to $5.4 \mathrm{~g} \mathrm{~L}^{-1}$ and $5.0 \mathrm{~g} \mathrm{~L}^{-1}$, respectively, in shake-flask cultivations (Fig. 1e). By contrast, other combinations failed to further improve the HA synthesis (Fig. 1e). 

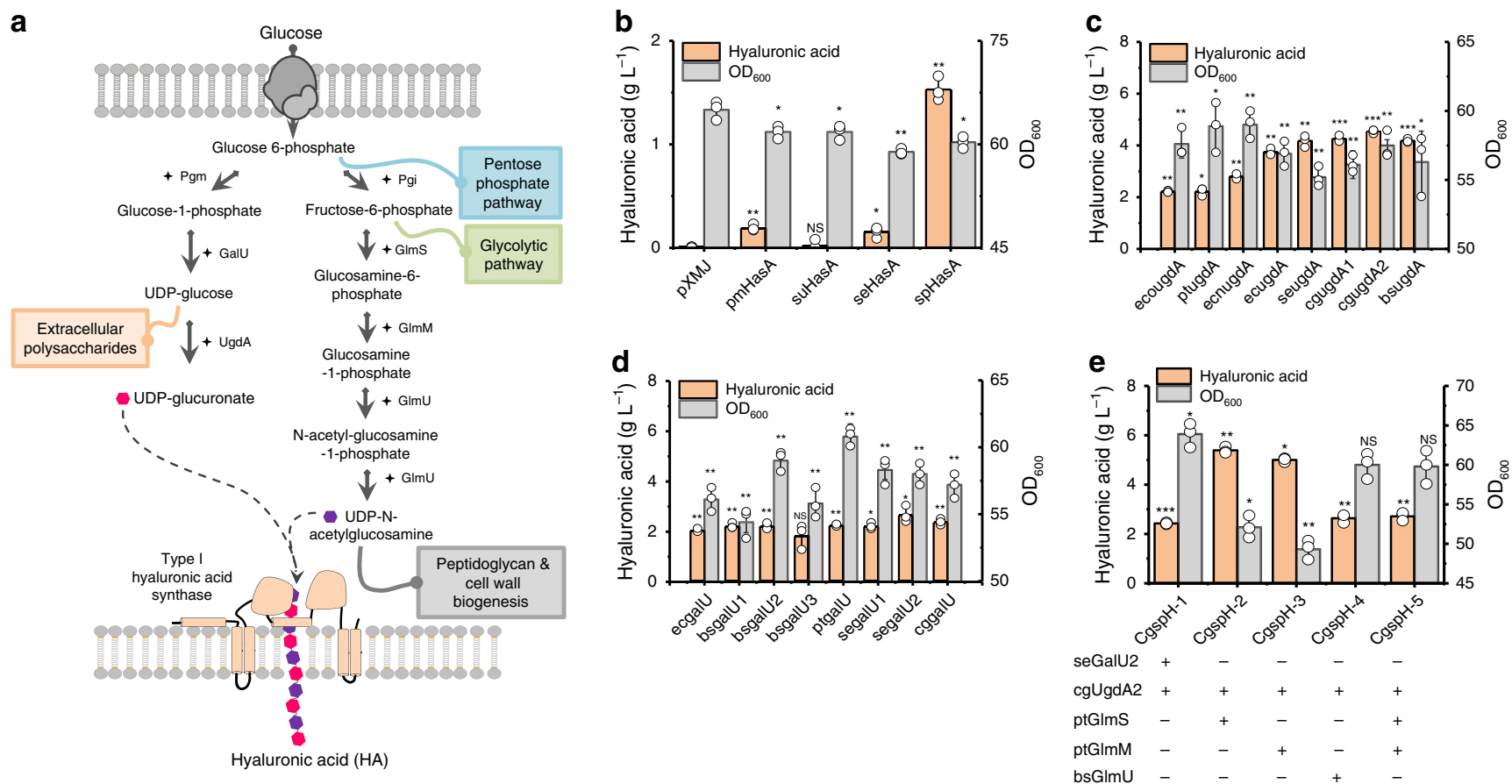

Fig. 1 Engineering C. glutamicum for HA biosynthesis from glucose. a HA chains are elongated by HA synthase (HasA) from two building blocks: UDPGIcA (uridine diphosphate glucuronate) and UDP-GIcNAc (uridine diphosphate N-acetylglucosamine). Pgm, phosphoglucomutase; GalU, glucose-1phosphate uridylyltransferase; UgdA, UDP-glucose 6-dehydrogenase; Pgi, glucose-6-phosphate isomerase; GImS, L-glutamine-D-fructose-6-phosphate aminotransferase; GImM, phosphoglucosamine mutase; GImU, UDP-N-acetylglucosamine pyrophosphorylase/Glucosamine-1-phosphate N-

acetyltransferase. b HA synthesis by P. multocida (pmHasA), S. pyogenes (spHas A), S. uberis (suHas A), and S. equi subsp. zooepidemicus HasA (seHasA), respectively in C. glutamicum. c, d Comparison of the activities of UgdA and GalU from different species on enhancing HA production. e Co-overexpression of $C$. glutamicum cgUgdA2 with S. equi subsp. zooepidemicus seGalU2, P. putida ptGImS, P. putida ptGlmM or B. subtilis bsGImU to enhance HA production. All the data are expressed as the mean \pm S.D. from three $(n=3)$ biologically independent replicates. Statistical evaluation ( $p$-value) compared to strain $\operatorname{pXMJ}(\mathbf{a})$, spHasA (b, c), or cgugdA2 (e) was performed by two-sided $t$-test. ${ }^{\star} p<0.05,{ }^{\star \star} p<0.01,{ }^{\star \star \star} p<0.001$; NS not significant ( $p \geq 0.05$ ). Source data underlying Fig. 1b-e are provided as a Source data file.

Enhancement of HA production by attenuating the biosynthesis of extracellular polysaccharides. We then investigated a pathway competing with HA synthesis, specifically the biosynthesis of extracellular polysaccharides, which is involved in consumption of key intermediate metabolites such as UDPglucose ${ }^{37}$, the precursor of UDP-GlcA (Fig. 1a). The corynebacterial cell wall contains a peptidoglycan-attached arabinogalactan structure, which is enveloped by mycolic acid and an outer layer of extracellular polysaccharides, proteins and lipids ${ }^{38}$ (Fig. 2a). The main components of corynebacterial extracellular polysaccharides (also considered as capsular polysaccharides or cell-surface polysaccharides) are arabinomannan, mannan and glucan $^{38,39}$. However, the genes required for biosynthesis of $C$. glutamicum cell-surface polysaccharides remain largely unknown. Taniguchi et al. ${ }^{40}$ reported that overexpression of C. glutamicum sigma factor SigD induced secretion of carbohydrate compounds and raised the expression levels of three glycosyltransferases genes (cg0420, cg0532, and cg1181). Following genome analysis, we found that $c g 0420$ locates in close proximity to the $w z x, w z y$, and $w z z$ genes (Fig. 2b). Because the Wzx/Wzy-dependent assembly pathway synthesizes the majority of bacterial cell-surface polysaccharides (Fig. $2 \mathrm{a})^{41}$, we speculated that $\operatorname{cg} 0420$ may participate in biosynthesis of C. glutamicum extracellular polysaccharides. Prior to cg0420 deletion, we found three other putative glycosyltransferase genes within the same genomic region (cg0424, cg0419, and cg0438) (Fig. 2b and Supplementary Fig. 5).

After many rounds of trials, we did not obtain single deletions for $\operatorname{cg} 0420, \operatorname{cg} 0419$, or $\operatorname{cg} 0438$. However, we were able to delete cg0424 to generate strain Delcg0424. Basing on Delcg0424, we further deleted cg0420 and constructed strain Delcg0420,0424. It was found that neither single cg0424 deletion nor double deletion of cg0420 and cg0424 impaired cell growth (Fig. 2c). Sugar constituent analysis of the Delcg0424 extracellular polysaccharides showed that the concentration of mannose decreased by $32 \%$ while the concentration of arabinose was not affected (Fig. 2d). The concentrations of mannose and arabinose released from strain Delcg0420,0424 extracellular polysaccharides hydrolysis decreased by $24 \%$ and $47 \%$ respectively, comparing to that of the strain Delcg0424 (Fig. 2d). Thus, Cg0424 and Cg0420 probably have the activities of mannosyltransferase and arabinosyltransferase to catalyze the formation of mannan and arabinomannan, respectively. Moreover, the synthesis of C. gultamicum cellsurface polysaccharides probably involves more glycosyltransferases, as the double deletion of $c g 0420$ and $\operatorname{cg} 0424$ does not abolish the synthesis of mannan or arabinomannan. Deletion of these putative glycosyltransferase genes positively influenced HA synthesis, as HA yield increased by $14.9 \%$ with double deletion of cg0424 and $c g 0420$ to $6.4 \mathrm{~g} \mathrm{~L}^{-1}$ in shake-flask cultures (Table 1). The optimal engineered C. glutamicum strain CgspH-7 underwent fed-batch cultivation. After consuming $166 \mathrm{~g} \mathrm{~L}^{-1}$ glucose, the HA titer reached $34.2 \mathrm{~g} \mathrm{~L}^{-1}$ (Fig. 2e) and the broth turned viscous (Supplementary Table 1).

HA accumulation encapsulates $C$. glutamicum cells. HA is produced as the main component of some bacterial capsules and is attached to the cell surface to provide protection and virulence. To determine how HA is released into culture broth and its distribution on the C. glutamicum surface, we visualized the 
a

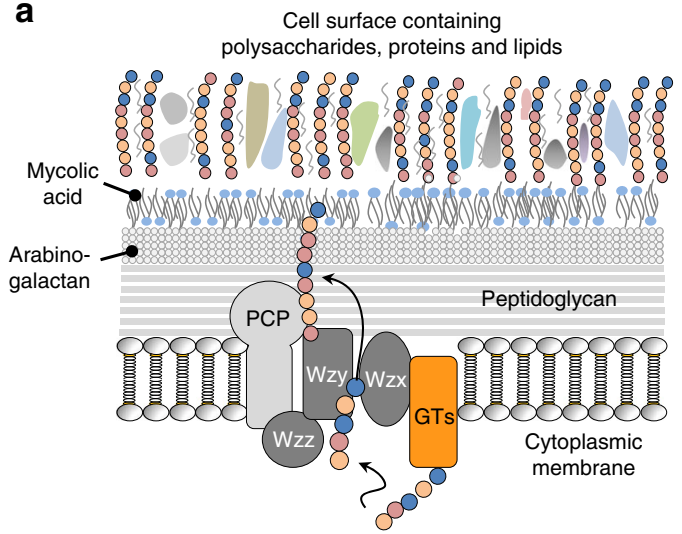

b

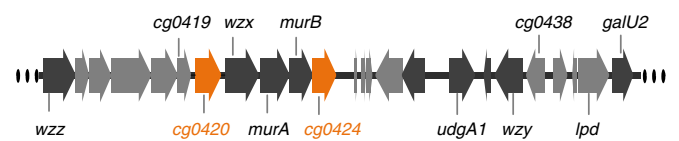

C

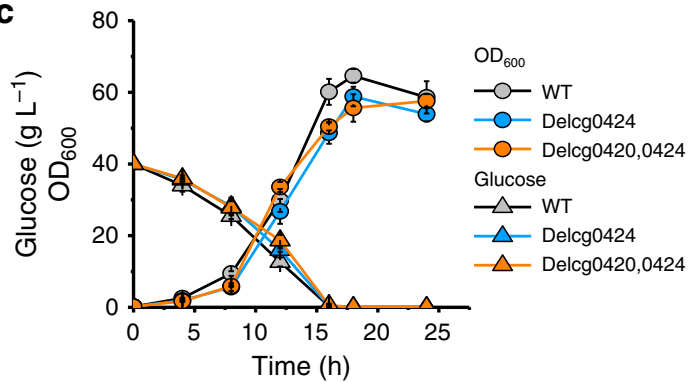

d

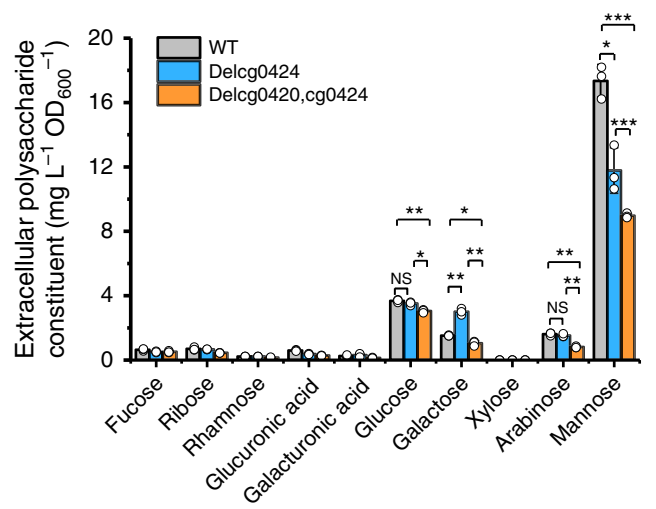

e

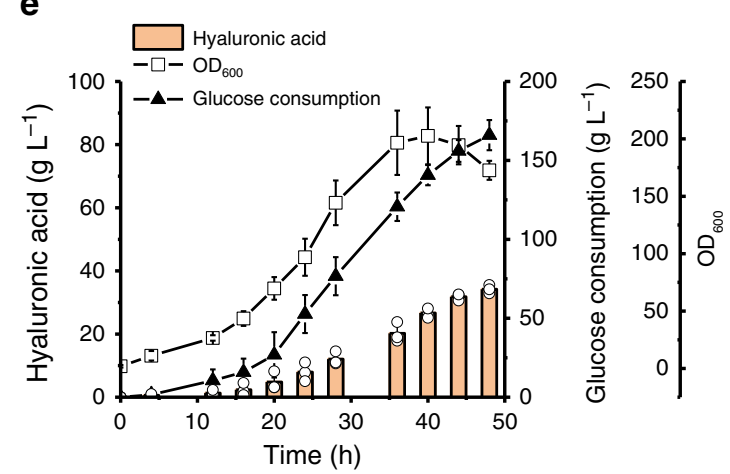

Fig. 2 Deletion of $\mathbf{c g 0 4 2 0}$ and $\mathbf{c g 0 4 2 4}$ to improve HA production. a The model of the C. glutamicum cell envelope structure 38,39 .

Extracellular polysaccharides/cell-surface polysaccharides, proteins and lipids are attached to the mycolic acid and arabinogalactan layer to form the outmost layer of the C. glutamicum cell wall. The Wzx/Wzy-dependent pathway predicted to participate in synthesis of cell-surface polysaccharides ${ }^{41}$. GTs, glycosyltransferases; PCP, polysaccharide co-polymerase. b Gene cluster putatively involved in synthesis of cell-surface polysaccharides. Genes cg0419, cg0420, cg0424, and cg0438 found in close proximity to wzx and wzy were predicted to code glycosyltransferases. c Growth and metabolism of $C$. glutamicum ATCC 13032 (WT), cg0424 deletion strain (Delcg0424) or cg0420 and cg0424 double deletion strain (Delcg0420,0424). d Sugar constituent of cell-surface polysaccharides isolated from C. glutamicum ATCC 13032 (WT), cg0424 deletion strain (Delcg0424) and cg0420 and cg0424 double deletion strain (Delcg0420,0424). e Fed-batch cultivation of $\mathrm{CgspH}-7$ in a 5-L fermenter. Real-time total consumed glucose, cell density $\left(\mathrm{OD}_{600}\right)$, and $\mathrm{HA}$ yield were plotted. Seed culture was inoculated by $10 \%(\mathrm{v} / \mathrm{v})$. Initial glucose content in the fed-batch culture was $40 \mathrm{~g} \mathrm{~L}^{-1}$. Post-inoculation glucose concentration was maintained at between 10 and $15 \mathrm{~g} \mathrm{~L}^{-1}$. Ammonia $[14 \%(\mathrm{v} / \mathrm{v})]$ was fed automatically to maintain pH at between 6.5 and 7.0 and air flow was maintained at $5 \mathrm{vvm}$. All the data are expressed as the mean \pm S.D. from three $(n=3)$ biologically independent replicates. Each biological replicate of HA concentration assay was presented as the mean value of three technical repeats. Statistical evaluation ( $p$-value) was performed by two-sided $t$-test. ${ }^{\star} p<0.05,{ }^{\star \star} p<0.01,{ }^{\star \star \star} p<0.001$; NS not significant $(p \geq 0.05)$. Source data underlying Fig. $2 c-e$ are provided as a Source data file.

Table 1 Increase HA productivity by gene deletion of $\mathrm{cg} 0424$ and $\mathrm{cg} 0420$.

\begin{tabular}{lllcl} 
Strain & Deleted gene & HA yield $\left(\mathbf{g ~ L}^{-\mathbf{1}}\right)^{\mathbf{a}}$ & Increase in HA yielda $^{\mathbf{a}}$ & $\boldsymbol{p}_{\text {-value }}$ \\
\hline $\mathrm{CgspH}-6$ & cg0424 & $5.8 \pm 0.1$ & $4.8 \% \pm 0.8 \%$ & $p=0.009$ \\
$\mathrm{CgspH}-7$ & cg0424 and $c g 0420$ & $6.4 \pm 0.1$ & $14.9 \% \pm 1.0 \%$ & $p=0.001$ \\
\hline
\end{tabular}

aThe increase in $\mathrm{HA}$ yields of strain of $\mathrm{CgspH}-6$ and $\mathrm{CgspH}-7$ were compared to the $\mathrm{HA}$ yield of strain $\mathrm{CgspH}-2$ presented in Fig. 1e. All the data are expressed as the mean \pm SD from three $(n=3)$ biologically independent replicates.

bStatistical evaluation ( $p$-value) compared to strain $\mathrm{CgspH}-2$ was performed by two-sided $t$-test.

HA-producing strains CgspH-2 and $\mathrm{CgspH}-7$ by phase-contrast microscopy and found that both strains exhibited cell aggregation along with HA accumulation (Fig. 3a). Moreover, the engineered C. glutamicum strains showed a chain-like morphology (Fig. 3a and Supplementary Fig. 6) resembling that of the native HAproducing Streptococcus species. To visualize HA distribution, we performed negative staining with nigrosin, a classical capsulestaining dye $\mathrm{e}^{42}$. Secreted HA formed a capsule-like layer, with HA-producing cells encapsulated (Fig. 3a), whereas no similar structure was observed in the control strain C. glutamicum pXMJpEC carrying blank vectors. As a consequence, we proposed a model of the encapsulation process (Fig. 3b). HA molecules were not secreted directly into the medium but rather knitted into a slime layer encapsulating the dividing cells. Additionally, the HA molecules are gradually released from the outer layer and dissolved in the culture broth. In the presence of adequate glucose, the size of the cell capsule grow continuously (Fig. 3a between time points 16 and 28 hour), whereas decreased glucose 
a

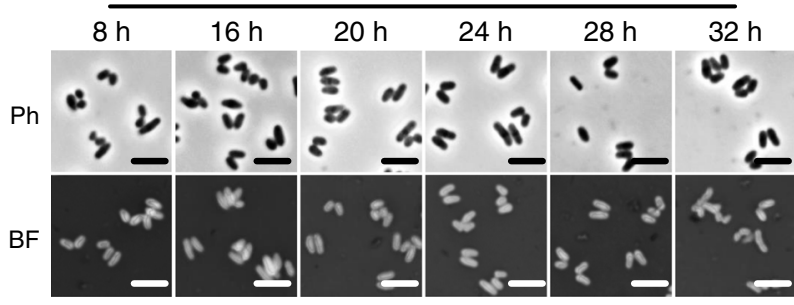

$\mathrm{CgspH}-2$

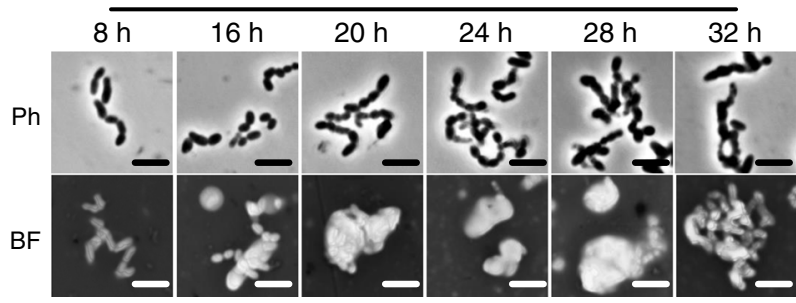

$\mathrm{CgspH}-7$

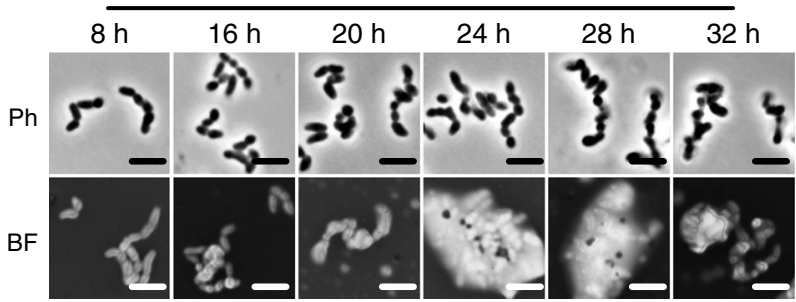

b

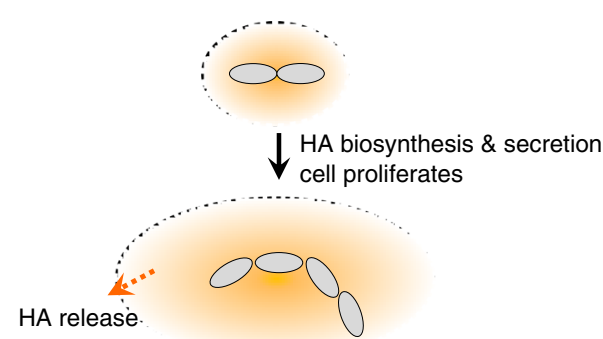

HA-cell encapsulation grows

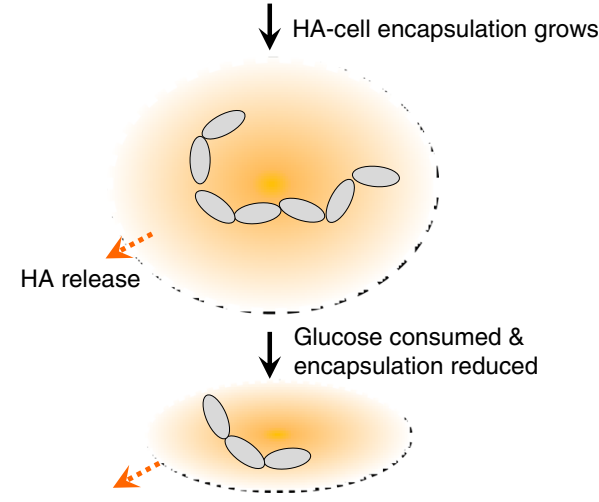

HA release

Fig. 3 Encapsulation of C. glutamicum cells by secreted HA. a Representative micrographs of C. glutamicum cells producing HA. Strains were cultivated in shake-flasks. Cells were collected at designated time points for visualization by phase-contrast microscopy or under a bright field after negative staining with $100 \mathrm{mg} \mathrm{mL}^{-1}$ water-soluble nigrosin for 5 minutes. Ph, phase-contrast microscopy; BF, bright-field microscopy. Scale bar, $2.5 \mu \mathrm{m}$. Microcopy experiments were performed three times independently with similar results. b A proposed model of HA secretion, encapsulation and release. Source data underlying Fig. 3a are provided as a Source data file.

availability at the late growth phase made HA secretion slow down and HA encapsulation decay (Fig. 3a, time point 32 hour). suggest that increased concentration of high-MW HA released into cultures also restricts nutrient uptake.
The HA capsule layer restricts nutrient uptake. The HA capsule layer of Streptococcus plays important roles in resisting phagocytosis and protecting the cells from desiccation and drying ${ }^{3}$. However, the influence of the HA capsule layer on cell metabolism remains unclear. Therefore, we used recombinant LHYal with high substrate specificity to disrupt the HA capsule layer of the native HA producer S. equi subsp. zooepidemicus WSH-24 to study the impact of HA capsule on cell metabolism ${ }^{9}$. Supplementation with LHYal $\left(6000 \mathrm{U} \mathrm{mL}^{-1}\right)$ disrupted the HA capsule of S. equi subsp. zooepidemicus (Fig. 4a). Additionally, the disruption of capsule sped up glucose consumption, stimulated cell growth and significantly increased HA yield (Fig. 4b). This result demonstrates that the presence of an HA capsule inhibited nutrient uptake and cell growth. The influence could be relieved by disruption of cell encapsulation by LHYal treatment (Fig. 4c). Moreover, we supplied different concentrations of high-MW HA (1.3 MDa) to cultures of C. glutamicum ATCC 13032, a non-HA producer, to examine the impact of HA that released into culture broth on cell growth and metabolism. In order to represent better the natural phenomenon, the HA supplemented here is produced by the natural HA producer $S$. equi subsp. zooepidemicus. We found significant decreases in cell growth and glucose consumption in the presence of $5 \mathrm{gL}^{-1} \mathrm{HA}$ and $10 \mathrm{gL}^{-1} \mathrm{HA}$ (Fig. 4d). By contrast, supplementing equal concentrations of HA pretreated with $10000 \mathrm{U} \mathrm{mL}^{-1}$ of LHYal for 8 hours did not slow down cell growth or glucose consumption (Fig. $4 \mathrm{~d}$ ). These results
Eliminating the capsule-like layer promotes HA production. We then determined whether elimination of the capsule-like layer of CgspH-7 would also be beneficial to cell growth and HA production. We supplemented $6000 \mathrm{U} \mathrm{mL}^{-1}$ LHYal to CgspH-7 shake-flask cultures upon initiation of HA accumulation. As expected, cell encapsulation did not show up when LHYal was supplemented and the chain-structured cell aggregates partially recovered to the natural rode shape of C. glutamicum (Fig. 5a). As a result, the glucose consumption and cell growth of CgspH-7 were enhanced and HA synthesis was accordingly promoted. No such effects were observed on the control strain pXMJ-pEC (Fig. 5b). Furthermore, addition of LHYal to fedbatch cultures of C. glutamicum CgspH-7 not only improved HA production, but also resulted in stronger metabolic activities and prolonged exponential phases (Fig. 6a-c). Supplementation of LHYal to a final concentration of 1500,3000 , or $6000 \mathrm{U} \mathrm{mL}^{-1}$ increased the total consumed glucose from $166 \mathrm{~g} \mathrm{~L}^{-1}$ (Fig. 2e) to $316 \mathrm{~g} \mathrm{~L}^{-1}$ (Fig. 6a), $424 \mathrm{~g} \mathrm{~L}^{-1}$ (Fig. 6b), and $440 \mathrm{~g} \mathrm{~L}^{-1}$ (Fig. 6c), respectively and increases in the $\mathrm{OD}_{600}$ from 172 (Fig. 2e) to 215 , 253, and 231 (Fig. 6a-c), respectively. Additionally, this improved HA production to $46.2 \mathrm{~g} \mathrm{~L}^{-1}$ (Fig. 6a), $57.5 \mathrm{~g} \mathrm{~L}^{-1}$ (Fig. 6b), and $74.1 \mathrm{~g} \mathrm{~L}^{-1}$ (Fig. 6c), whereas the weight average MW of HA decreased to $155 \mathrm{kDa}, 91 \mathrm{kDa}$ and $53 \mathrm{kDa}$, respectively (Table 2). These results demonstrated that elimination of the capsule-like layer recovered cell metabolism rate and improved HA production. 
a

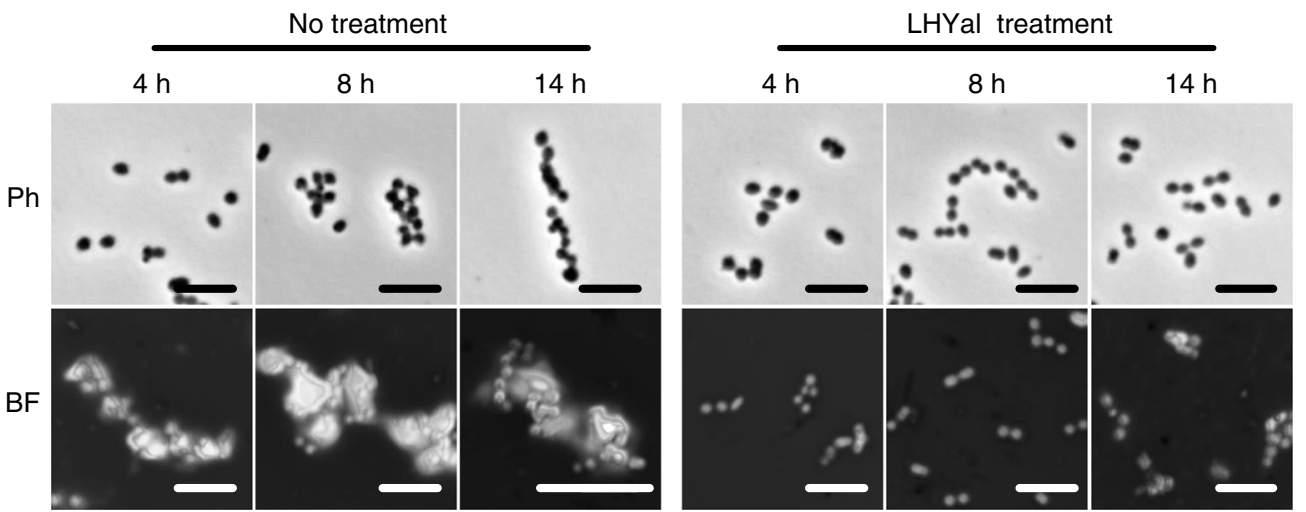

b

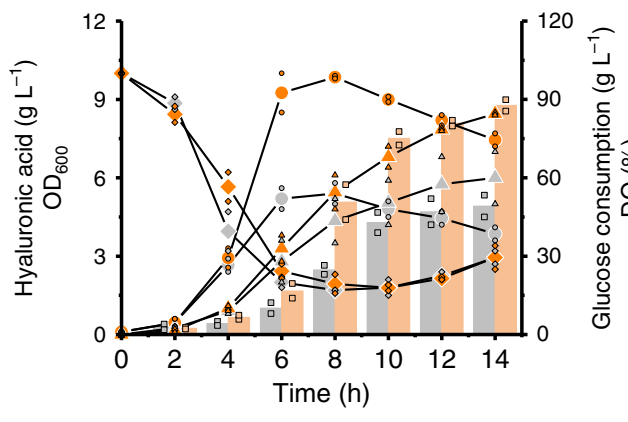

d

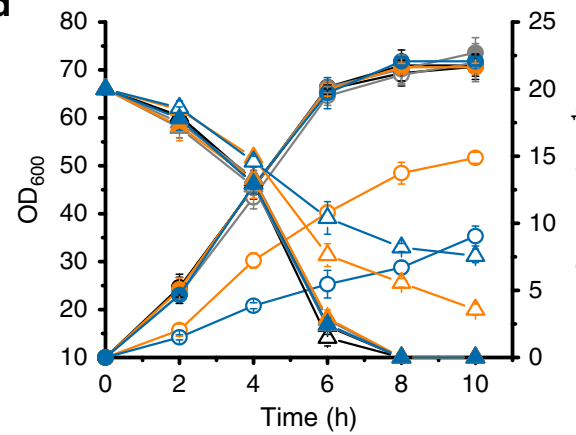

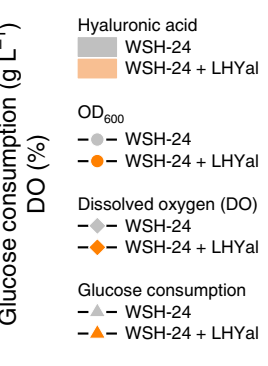

$\mathrm{OD}_{600}$

$-0-0 \mathrm{~g} \mathrm{~L}^{-1} \mathrm{HA}$

$-0 \mathrm{~g} \mathrm{~L}^{-1} \mathrm{HA}+\mathrm{LHYa}$

$-\mathrm{O}-3 \mathrm{~g} \mathrm{~L}^{-1} \mathrm{HA}$

$-3 \mathrm{gL}^{-1} \mathrm{HA}+\mathrm{LHYal}$

$-\mathrm{O}-5 \mathrm{~g} \mathrm{~L}^{-1} \mathrm{HA}$

$-5 \mathrm{~g} \mathrm{~L}^{-1} \mathrm{HA}+\mathrm{LHYa}$

$-\mathrm{O}-10 \mathrm{~g} \mathrm{~L}^{-1} \mathrm{HA}$

$-10 \mathrm{~g} \mathrm{~L}^{-1} \mathrm{HA}+\mathrm{LHYal}$

Glucose

$-\triangle-0 \mathrm{~g} \mathrm{~L}^{-1} \mathrm{HA}$

$-\mathbf{A}-0 \mathrm{~g} \mathrm{~L}^{-1} \mathrm{HA}+\mathrm{LHYal}$

$-\triangle-3 \mathrm{~g} \mathrm{~L}^{-1} \mathrm{HA}$

$-\mathbf{A}-3 \mathrm{~g} \mathrm{~L}^{-1} \mathrm{HA}+\mathrm{LHYal}$

$-\triangle-5 \mathrm{~g} \mathrm{~L}^{-1} \mathrm{HA}$

$-\triangle-5 \mathrm{~g} \mathrm{~L}^{-1} \mathrm{HA}+\mathrm{LHYal}$

$-\triangle-10 \mathrm{~g} \mathrm{~L}^{-1} \mathrm{HA}$

- $-10 \mathrm{~g} \mathrm{~L}^{-1} \mathrm{HA}+$ LHYal
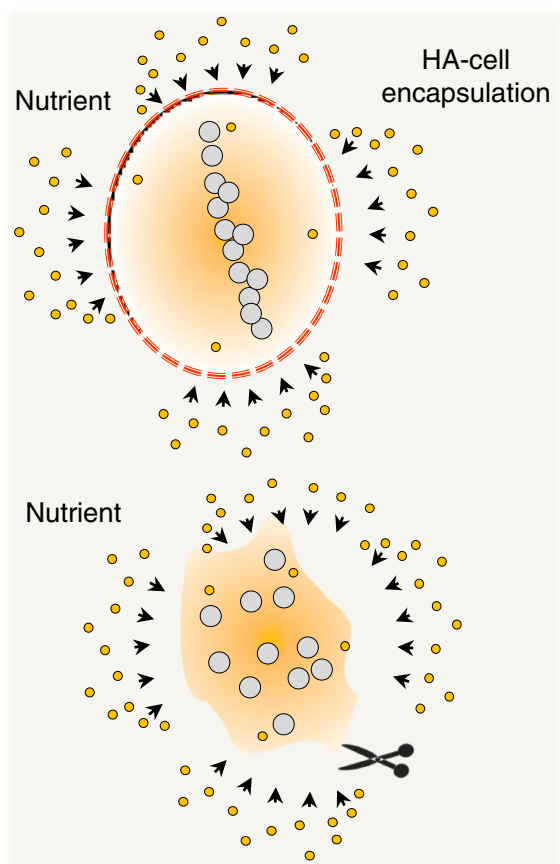

Hyaluronidase treatment disrupts HA-cell encapsulation

Fig. 4 The HA encapsulation inhibits cell growth and glucose uptake. a Representative micrographs of HA-producing S. equi subsp. zooepidemicus WSH24 cultivated in a 3-L fermenter (refer to $\mathbf{b}$ for the cultivation details) in the presence or absence of $6000 \mathrm{U} \mathrm{mL}-1$ of LHYal. Ph, phase-contrast microscopy; $\mathrm{BF}$, bright-field microscopy. Scale bar, $2.5 \mu \mathrm{m}$. Microcopy experiments were performed two times independently with similar results. b $\mathrm{S}$. equi subsp. zooepidemicus WSH-24 cultivated by fed-batch cultivation in a 3-L fermenter to produce HA in the presence of an initial glucose concentration at $70 \mathrm{~g} \mathrm{~L}^{-1}$ and post-inoculation glucose concentration at between 10 and $15 \mathrm{~g} \mathrm{~L}^{-1}$. Total consumed glucose instead of real-time glucose concentration was plotted. LHYal (6000 $\mathrm{U} \mathrm{mL}^{-1}$, final concentration) was added at the beginning of cultivation. c A schematic showing HA encapsulation hinders nutrient uptake. LHYal inhibits HA encapsulation and increases nutrient availability. d Effect of HA dissolved in culture broth (weight average MW $1.3 \mathrm{MDa}$ ) on glucose uptake by wild-type C. glutamicum ATCC 13032. b The data are expressed as the mean from two $(n=2)$ biologically independent replicates. Each biological replicate of HA concentration assay is presented as the mean value of three technical repeats. The values of each biologically independent replicate are indicated with same-colored symbols with smaller size. $\mathbf{d}$ The data are expressed as the mean \pm SD from three $(n=3)$ biologically independent replicates. Source data underlying Fig. $4 a, b$ and $d$ are provided as a Source data file.

\section{Discussion}

Construction of biosynthesis pathways of HA and other glycosaminoglycans in genetically engineered microbes represents a green and safe method for production of these invaluable compounds. To construct an efficient HA-producing cell factory, selection of a proper HA synthase is critical, given that HA productivity and MW are largely determined by synthase activity ${ }^{19}$. Most HA synthases are found in vertebrates, whereas bacterial HA synthases are mainly found in the group A Strepto$\operatorname{coccus}^{3}$. Streptococcal HasA has four transmembrane helices and two membrane-associated helices ${ }^{33-35}$; therefore, it is conceivable that the membrane microenvironment influences HasA activity. In the present study, we found that spHasA displayed stronger HA-synthesis activities in C. glutamicum and resulted in higher HA accumulation relative to HasA from the other species (Fig. 1b). The differences in the sequences of these enzymes were primarily found in the transmembrane region (Supplementary Fig. 2a), suggesting that spHasA might be better suited to the $C$. glutamicum cytoplasmic membrane. Recently, Westbrook et al. ${ }^{27}$ successfully enhanced the activity of Streptococcus equisimilis 
HasA (sseHasA) in B. subtilis by regulating membrane cardiolipin content and distribution. Additionally, previous studies engineered E. coli species as alternative HA producers ${ }^{10,11,43}$.
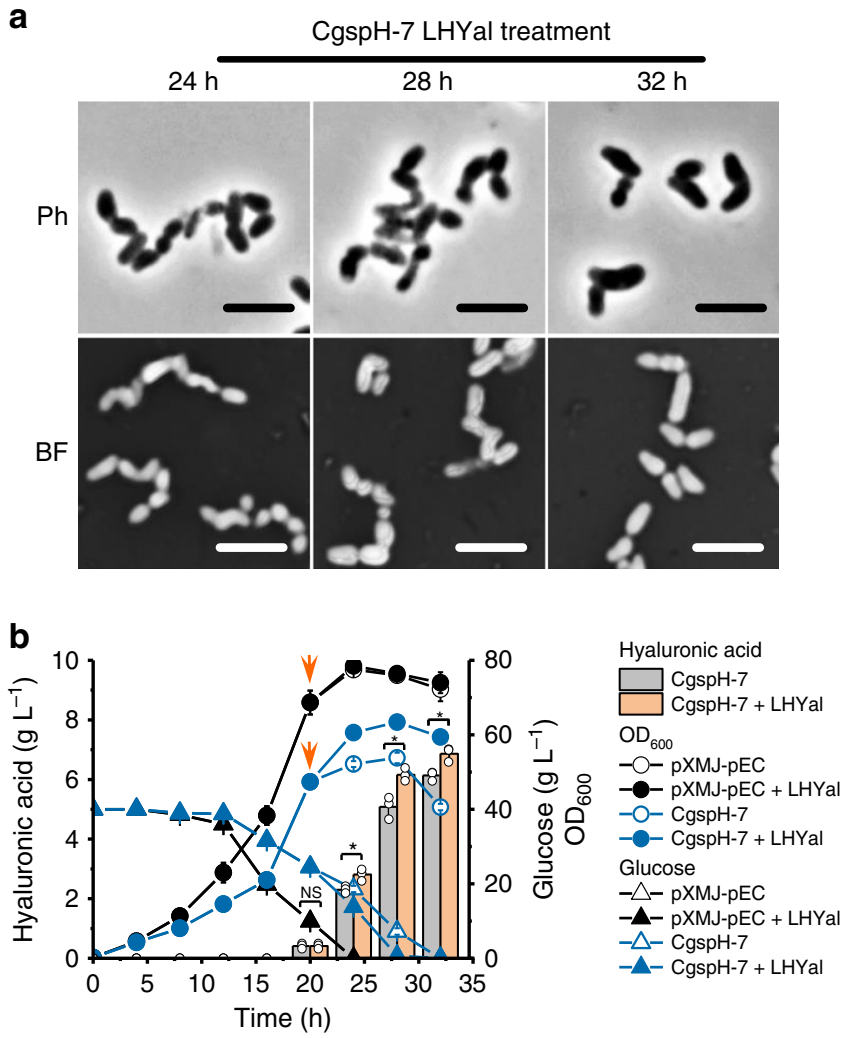

Fig. 5 Disruption of HA encapsulation promotes $C$. glutamicum cell growth and HA synthesis. a Representative micrographs of $\mathrm{CgspH}-7$ supplemented with $6000 \mathrm{U} \mathrm{mL}^{-1}$ LHYal after 20 hours of shake-flask cultivation (refer to $\mathbf{b}$ for the cultivation details). Cell encapsulation was disrupted by LHYal. Ph, phase-contrast microscopy; BF bright-field microscopy. Scale bar, $2.5 \mu \mathrm{m}$. Microcopy experiments were performed three times independently with similar results. b LHYal stimulated cell growth, glucose metabolism, and $\mathrm{HA}$ production by the $\mathrm{CgspH}-7$ strain. Time point of LHYal supplementation was indicated with arrows. All the data are expressed as the mean \pm S.D. from three $(n=3)$ biologically independent replicates. Statistical evaluation ( $p$-value) was performed by two-sided $t$-test. ${ }^{\star} p<0.05,{ }^{{ }^{\star}} p<0.01,{ }^{\star \star \star} p<0.001$; NS, not significant $(p \geq$ 0.05 ). Source data underlying Fig. $5 a, b$ are provided as a Source data file.
However, E. coli exhibit a low degree of activity by heterologously expressed HA synthases, possibly because of the inherent incompatibility between HA synthase and the Gram-negative $E$. coli cell structure: $E$. coli cells have two membranes, whereas the type I HA synthase from Gram-positive Streptococcus secretes HA chains only through the inner membrane. Protein engineering of $\mathrm{HasA}^{44}$, especially changes in the transmembrane region, might represent a possible direction for further improvements in HA production (Supplementary Fig. 2b, c).

In addition to overexpressing UgdA and GlmS for precursor generation (Fig. 1a), deletion of the competing pathway to increase the supply of UDP-glucuronate and UDP-GlcNAc is a commonly used strategy 22,29 . In C. glutamicum, there is less availability of UDP-GlcA relative to UDP-GlcNAc, given that overexpression of UgdA improved HA yield by 2-fold (Fig. 1c). Additionally, UDP-GlcNAc is naturally produced for peptidoglycan biosynthesis (Fig. 1a), which is critical for cell survival. UDP-glucose, the precursor of UDP-GlcA, is used to construct the outmost layer of the C. glutamicum cell wall ${ }^{38}$, which should be less important to the cell than peptidoglycans for maintaining the cell-envelope structure. A previous report showed that $c g 0420$ expression enhanced the biosynthesis of extracellular polysaccharides $^{40}$. In the present study, we selected four putative genes encoding glycosyltransferases (cg0420, cg0424, cg0419, and cg0438) and located in close proximity to galU and ugdA for deletion, finding that loss of cg0424 and cg0420 reduced cellsurface polysaccharides such as mannan and arabinomannan (Fig. 2d) and enhanced HA production (Table 1) without impairing cell growth (Fig. 2c). These results demonstrated that the enzymes encoded by $c g 0420^{40}$ and $c g 0424$ are involved in extracellular polysaccharide synthesis and that the outmost layer of the C. glutamicum cell wall ${ }^{38}$ comprising extracellular polysaccharides is likely not essential to cell growth.

Table 2 Weight average MW of HA produced in fed-batch cultivations supplemented with different titers of LHYal.

\begin{tabular}{llll} 
Strain & LHYal (U $\left.\mathbf{~ m L}^{-1}\right)$ & $\begin{array}{l}\text { Sampling time } \\
\text { poit (hour) }\end{array}$ & MW (kDa) \\
\hline CgspH-7 & None & 48 & $331(306,357)$ \\
& 1500 & 72 & $155(135,175)$ \\
& 3000 & 72 & $91(92,89)$ \\
& 6000 & 72 & $53(56,51)$
\end{tabular}

aThe data are expressed as the mean from two $(n=2)$ biologically independent replicates which are indicated in brackets.
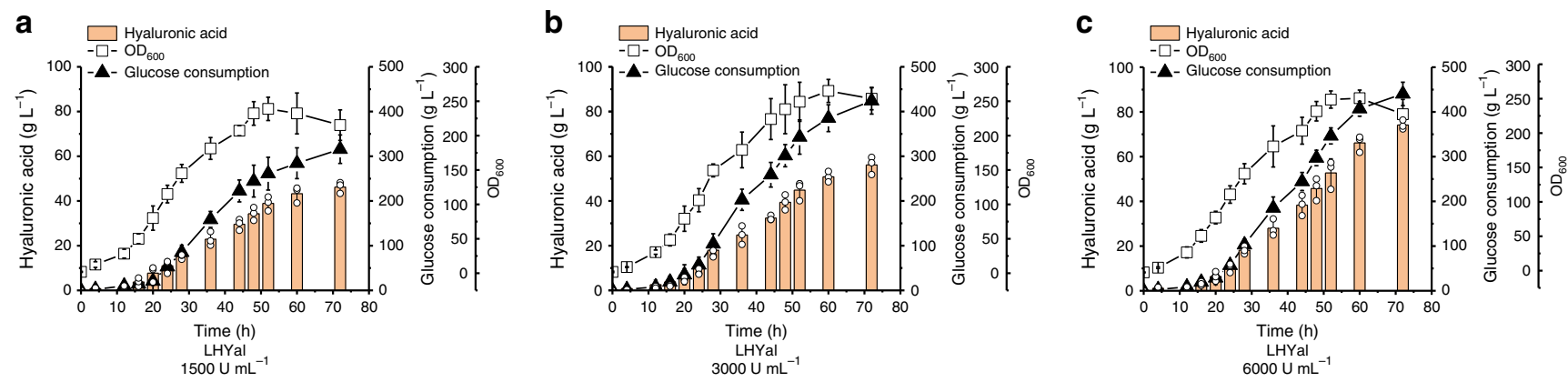

Fig. 6 Fed-batch cultivation of $\mathbf{~ G g s p H - 7 ~ s u p p l e m e n t e d ~ w i t h ~ d i f f e r e n t ~ c o n c e n t r a t i o n s ~ o f ~ L H Y a l ~ t o ~ i n c r e a s e ~ H A ~ b i o p r o d u c t i o n . ~} 1500 \mathrm{U} \mathrm{mL}^{-1}$ (a), $3000 \mathrm{U}$ $\mathrm{mL}^{-1}(\mathbf{b})$, and $6000 \mathrm{U} \mathrm{mL}-1$ (c) final concentrations of LHYal were supplemented to the fed-batch cultures of CgspH-7. Total consumed glucose, cell density $\left(\mathrm{OD}_{600}\right)$ and $\mathrm{HA}$ yields were plotted. During cultivation, glucose was fed manually to maintain a concentration at between 10 and $15 \mathrm{~g} \mathrm{~L}^{-1}$, and ammonia $[14 \%(\mathrm{v} / \mathrm{v})]$ was supplemented to maintain $\mathrm{pH}$ at between 6.5 and 7.0. All the data are expressed as the mean \pm S.D. from three $(n=3)$ biologically independent replicates. Each biological replicate of HA concentration assay is presented as the mean value of three technical repeats. Source data are provided as a Source data file. 
The feedback effects of HA accumulation on cell morphology and metabolism have previously been ignored. Here, we found that during the later period of fermentation, cells of the engineered C. glutamicum strain were encapsulated following HA accumulation. The formation of a capsule-like layer (Fig. 3a) inhibited cell metabolism and growth (Fig. 4b). The morphology of the C. glutamicum CgspH-7 cells resembled the chain shape of native HA-producing Streptococcus species (Fig. 4a). Moreover, our results suggest that the capsule of pathogens not only protects cells against various stressors or phages or acts as a virulence factor, but also could adversely affect cell metabolism (Fig. 4b). This could explain why capsule formation occurs under so complex regulatory processes ${ }^{45}$.

In conclusion, optimization of the HA-biosynthesis pathway, inactivation of extracellular polysaccharide biosynthesis, destruction of cell encapsulation and resolving the mass-transfer bottleneck by supplementation with LHYal resulted in an efficient C. glutamicum cell factory and a fermentation approach. This engineered strain allowed generation of an average of $74.1 \mathrm{~g} \mathrm{~L}^{-1}$ HA with an MW of $53 \mathrm{kDa}$ in 5-L fed-batch cultures (Fig. $6 \mathrm{c}$ and Table 2). The results and strategies reported here are likely applicable to the production of other biopolymers.

\section{Methods}

Plasmids and strains. Plasmids and strains used in this study are listed in Supplementary Data 1 and Supplementary Data 2. We used E. coli JM109 for plasmid amplification and recombinant plasmid construction. C. glutamicum ATCC 13032 was used as the parental strain for breeding all engineered C. glutamicum strains. HA synthase genes (hasA) were amplified from the genome of $S$. equi subsp. zooepidemicus (se) or synthesized by GENEWIZ (Suzhou, China) according to the published genome sequences of Streptococcus pyogenes ( $\mathrm{sp}$ ), Streptococcus uberis (su) and Pasteurella multocida (pm). The hasA genes were prefixed with "se", "sp", "su", and "pm" in order to indicate species origins.

After amplification with the designated primers sehasA-F and sehasA-R, sphasA-F and sphasA-R, suhasA-F and suhasA-R and pmhasA-F and pmhasA-R (Supplementary Data 3), hasA genes were ligated into HindIII/BamHI linearized pXMJ19 using the T5 exonuclease DNA assembly (TDEA) method ${ }^{46}$ to generate the plasmids pXMJ19-sehasA, pXMJ19-sphasA, pXMJ19-suhasA, and pXMJ19pmhasA. With the former three plasmids as templates, the linear form of plasmids pXMJ19-sphasA-6His, pXMJ19-sehasA-6His, pXMJ19-suhasA-6His, pXMJ19sehas ${ }^{\text {Thr7-Met25 }}$ were generated via PCR using designated primers listed in Supplementary Data 3. The PCR products carrying homogenous $5^{\prime}$ and $3^{\prime}$ terminals (included in the designed primers) were transformed into E. coli JM109 after purification and cyclized by the endogenous DNA recombinases. The plasmid pXMJ19-sehasA Thr7-Met25-6His was constructed by PCR in the same way using pXMJ19-sehasA ${ }^{\text {Thr7-Met25 }}$ as template. Genes encoding enzymes capable of synthesizing HA building blocks, including galU (encoding glucose-1-phosphate uridylyltransferase), ugdA (encoding UDP-glucose 6-dehydrogenase), glmM (encoding phosphoglucosamine mutase), glmS (encoding L-glutamine:D-fructose-6phosphate aminotransferase), $g \operatorname{lm} U$ (encoding bifunctional $\mathrm{N}$-acetylglucosamine1-phosphate uridyltransferase and glucosamine-1-phosphate acetyltransferase), were amplified from different species, including E. coli MG1655 (ec), P. putida KT2440 (pt), S. equi subsp. zooepidemicus (se) and C. glutamicum ATCC13032 $(\mathrm{cg})$, using the designated primers listed in Supplementary Data 3. Additionally, we cloned the $u g d A$ genes located in the heparosan synthesis gene cluster of $E$. coli O10:K5:H4 and E. coli Nissle 1917. The primers and the amplified genes were prefixed with "ec", "pt", "se", "cg", "eco", and "ecn" in order to indicate their species origins. These genes were assembled individually or in specified combinations into the pEC-XK99E plasmid using the TEDA method ${ }^{46}$.

Homologous regions with a length of $\sim 750 \mathrm{bp}$ were amplified upstream and downstream of $c g 0420$ and $c g 0424$ using primers 0420-up-F/0420-up-R, 0420down-F/0420-down-R, and 0424-up-F/0424-up-R, 0424-down-F/0424-down-R, respectively. The homologous regions were combined with the EcoRI/BamHI linearized pK18mobSacB plasmid with to create pK18mobSacB-0420 and pK18mobSacB-0424, which were subsequently used for gene deletions of $\operatorname{cg} 0420$ and $\operatorname{cg} 0424$.

All plasmids were transferred to C. glutamicum ATCC 13032 by electroporation (200 $\Omega, 12.5 \mathrm{kV} \mathrm{cm}^{-1}$, pulse duration $4 \mathrm{~ms}$ ) and a subsequent heat shock $\left(46^{\circ} \mathrm{C}\right.$ for 6 minutes in BHIS medium $)^{47}$. Recombinant strains were selected with kanamycin resistance. In the same way, integrations of the plasmids pK18mobSacB-0420 and pK18mobSacB-0424 into the chromosome were selected with kanamycin resistance. Segregation of the plasmids from chromosome was counter-selected with sucrose-induced lethality ${ }^{47}$. Loss of the gene $\operatorname{cg} 0420$ or $c g 0424$ was confirmed with colony PCR and DNA sequencing.
Medium and cultivation. E. coli was cultivated in Luria-Bertani medium (tryptone $10 \mathrm{~g} \mathrm{~L}^{-1}, \mathrm{NaCl} 10 \mathrm{~g} \mathrm{~L}^{-1}$, yeast extract $5 \mathrm{~g} \mathrm{~L}^{-1}, \mathrm{pH} 7.0$ ) at $37^{\circ} \mathrm{C}$, and C. glutamicum was cultivated at $30^{\circ} \mathrm{C}$ in BHIS medium $\left[37 \mathrm{~g} \mathrm{~L}^{-1}\right.$ Brain Heart Infusion (Difco), $91 \mathrm{~g} \mathrm{~L}^{-1}$ sorbitol]. Competent C. glutamicum cells for electroporation were prepared by cultivating C. glutamicum strains in BHIS medium to $\mathrm{OD}_{600}$ of 1.5 and washing cells three times with $10 \%(\mathrm{v} / \mathrm{v})$ glycerol $^{47}$. Chloramphenicol $\left(15 \mathrm{mg} \mathrm{L}^{-1}\right)$, kanamycin $\left(25 \mathrm{mg} \mathrm{L}^{-1}\right)$ or sucrose $[15 \%(\mathrm{~m} / \mathrm{v})]$ was supplemented, as necessary.

To produce HA in shake-flasks, engineered C. glutamicum strains were cultivated at $28^{\circ} \mathrm{C}$ with shaking at $200 \mathrm{rpm}$ in a modified glucose-corn steep powder medium ${ }^{29}$. The medium contained $40 \mathrm{~g} \mathrm{~L}^{-1}$ glucose, $20 \mathrm{~g} \mathrm{~L}^{-1}$ corn steep powder, $20 \mathrm{~g} \mathrm{~L}^{-1}(\mathrm{NH} 4)_{2} \mathrm{SO}_{4}, 1 \mathrm{~g} \mathrm{~L}^{-1} \mathrm{KH}_{2} \mathrm{PO}_{4}, 1 \mathrm{gL}^{-1} \mathrm{~K}_{2} \mathrm{HPO}_{4}, 0.25 \mathrm{~g} \mathrm{~L}^{-1}$ $\mathrm{MgSO}_{4}$, and $42 \mathrm{~g} \mathrm{~L}^{-1}$ MOPS [3-(N-morpholino) propanesulfonic acid]. The initial optical density at $600 \mathrm{~nm}\left(\mathrm{OD}_{600}\right)$ of the shake-flask cultivation was 0.2 , and isopropyl- $\beta$-D-thiogalactoside (IPTG) was added to induce target gene expression at time point 2.5 hour. LHYal was supplemented at time point 20 hour to a final concentration of $6000 \mathrm{U} \mathrm{mL}^{-1}$, as necessary.

Fed-batch cultivations of C. glutamicum were performed in a 5-L fermenter with $2.5 \mathrm{~L}$ of the glucose-corn steep powder medium. Seed cultures were prepared in glucose-corn steep powder medium containing $40 \mathrm{~g} \mathrm{~L}^{-1}$ glucose at $30^{\circ} \mathrm{C}$ and shaken at $220 \mathrm{rpm}$ for $8-10$ hours. During fed-batch cultivations, glucose [70\% (m/ v)] was fed according to real-time glucose consumption in order to dynamically maintain its concentration between 10 and $15 \mathrm{~g} \mathrm{~L}^{-1}$. Ammonia solution [14\% (v/ v)] was automatically fed in order to maintain the culture $\mathrm{pH}$ at between 6.5 and 7.0. Air flow was maintained at $\sim 5 \mathrm{vvm}$. LHYal was supplemented to final concentrations of 1500,3000 , or $6000 \mathrm{U} \mathrm{mL}^{-1}$ at time point 20 hour.

S. equi subsp. zooepidemicus WSH-24 seed culture was grown at $37^{\circ} \mathrm{C}$ and shaking at $220 \mathrm{rpm}$ for $14-16$ hours in medium containing $20 \mathrm{~g} \mathrm{~L}^{-1}$ glucose, $20 \mathrm{~g} \mathrm{~L}^{-1}$ yeast extract, $2 \mathrm{~g} \mathrm{~L}^{-1} \mathrm{MgSO}_{4} \cdot 7 \mathrm{H}_{2} \mathrm{O}, 0.1 \mathrm{~g} \mathrm{~L}^{-1} \mathrm{MnSO}_{4} \cdot 4 \mathrm{H}_{2} \mathrm{O}, 1.5 \mathrm{~g} \mathrm{~L}^{-1}$ $\mathrm{Na}_{2} \mathrm{HPO}_{4}, 0.64 \mathrm{~g} \mathrm{~L}^{-1} \mathrm{NaH}_{2} \mathrm{PO}_{4}, 2.0 \mathrm{~g} \mathrm{~L}^{-1} \mathrm{KH}_{2} \mathrm{PO}_{4}, 0.5 \mathrm{~g} \mathrm{~L}^{-1} \mathrm{NaHCO}_{3}, 20 \mathrm{~g} \mathrm{~L}^{-1}$ $\mathrm{CaCO}_{3}, 200 \mu \mathrm{g} \mathrm{L}^{-1} \mathrm{CaCl}_{2}, 46 \mu \mathrm{g} \mathrm{L}^{-1} \mathrm{ZnCl}_{2}, 19 \mu \mathrm{g} \mathrm{L}^{-1} \mathrm{CuSO}_{4} \cdot 5 \mathrm{H}_{2} \mathrm{O}, \mathrm{pH} 7.2$. Seed cultures were inoculated into a $3-\mathrm{L}$ fermenter containing $1.5 \mathrm{~L}$ of fermentation medium with a composition of $70 \mathrm{~g} \mathrm{~L}^{-1}$ glucose, $20 \mathrm{~g} \mathrm{~L}^{-1}$ yeast extract, $6.2 \mathrm{~g} \mathrm{~L}^{-1} \mathrm{Na}_{2} \mathrm{HPO}_{4}, 1.3 \mathrm{~g} \mathrm{~L}^{-1} \mathrm{~K}_{2} \mathrm{SO}_{4}, 2 \mathrm{~g} \mathrm{~L}^{-1} \mathrm{MgSO}_{4} \cdot 7 \mathrm{H}_{2} \mathrm{O}, 200 \mu \mathrm{g} \mathrm{L}^{-1}$ $\mathrm{CaCl}_{2}, 46 \mu \mathrm{g} \mathrm{L}^{-1} \mathrm{ZnCl}_{2}, 19 \mu \mathrm{g} \mathrm{L}-1 \mathrm{CuSO}_{4} \cdot 5 \mathrm{H}_{2} \mathrm{O}, \mathrm{pH}$ 7.2. For fed-batch cultivation at $37^{\circ} \mathrm{C}, \mathrm{NaOH}(5 \mathrm{M})$ was automatically fed to maintain $\mathrm{pH}$ between 6.9 and 7.1, and air flow was maintained at $\sim 3 \mathrm{vvm}$. LHYal (final concentration $6000 \mathrm{U} \mathrm{mL}^{-1}$ ) was supplemented at the time of seed inoculation.

Measurement of cell growth and metabolite concentration. Cell growth was monitored by changes in the $\mathrm{OD}_{600}$. Real-time glucose concentration was measured using an M-100 biosensor analyzer (Shenzhen Siemantec Technology, Shenzhen, China). To measure total HA, culture broths were autoclaved at $121^{\circ} \mathrm{C}$ for 30 minutes. Cell debris was removed by centrifugation at $16,099 \times g$ for 15 minutes Supernatants were pooled and mixed with four volumes of ice-cold ethanol and $\mathrm{HA}$ was precipitated at $-30^{\circ} \mathrm{C}$ overnight. Insoluble fractions were subsequently collected by centrifugation at $16,099 \times g$ for 10 minutes. Residual ethanol was evaporated at room temperature and the semi-dry insoluble fraction was dissolved in deionized water, whereas the water-insoluble fraction was removed by centrifugation. To remove as much impurity, these steps were repeated three times more. After appropriate dilution (5-1000 fold, depending on HA concentration), HA content was determined via carbazole assay using glucuronic acid as an external standard ${ }^{48}$. Supernatants from C. glutamicum culture harboring the blank vector pXMJ19 or pXMJ19/pEC-XK99E were used as the negative control. To measure secreted HA, cells were removed from the broth by centrifugation at $16,099 \times g$ for 15 minutes and HA was precipitated from the supernatant for measurement, as described above.

Analysis of C. glutamicum extracellular polysaccharides. C. glutamicum ATCC 13032 and strains lacking cg0424 or cg0420 and cg0424 were cultivated in CGXII minimal medium ${ }^{47}$ at $28^{\circ} \mathrm{C}$ for $48 \mathrm{~h}$. Cells were shaken with glass beads at $200 \mathrm{rpm}$ and room temperature for $1 \mathrm{~h}$ to release surface exposed materials including extracellular polysaccharides ${ }^{38}$. Cells were removed by centrifugation at $7155 \times g$ for 20 minutes. Supernatants were pooled and hydrolyzed with trifluoroacetic acid at $110{ }^{\circ} \mathrm{C}$ for 2 hours. Hydrolysates containing reducing sugars were dried in vacuum chamber at $65^{\circ} \mathrm{C}$ for 2 hours. Reducing sugars generated from hydrolysis of extracellular polysaccharides reacted with 1-phenyl-3-methyl-5-pyrazolone (PMP) at $70{ }^{\circ} \mathrm{C}$ for 60 minutes in the $\mathrm{NaOH}$-methanol solution to form the sugar$\mathrm{PMP}^{49}$. The sugar constituent of C. glutamicum extracellular polysaccharides was analyzed using Agilent 1200 HPLC system equipped with a SHISEIDO CAPCELL $\mathrm{PAK} \mathrm{C}_{18}$ column (inner diameter $4.6 \mathrm{~mm}$, length $250 \mathrm{~mm}$, particle size $5 \mu \mathrm{m}$ ). Chemicals were separated in the column using a mobile phase of $0.1 \mathrm{M} \mathrm{KH}_{2} \mathrm{PO}_{4}$ $(\mathrm{pH} 6.8)[82 \%(\mathrm{v} / \mathrm{v})]$ and acetonitrile $[18 \%(\mathrm{v} / \mathrm{v})]$ with a flow rate of $1 \mathrm{~mL} \mathrm{~min}^{-1}$ Fractions were detected with absorbance at wavelength of $245 \mathrm{~nm}$.

Preparation of recombinant leech hyaluronidase. LHYal samples were prepared and purified from recombinant Pichia pastoris through Ni-sepharose affinity resin (HisTrap FF column, GE Healthcare) ${ }^{32}$. Purified LHYal was stored at $-30^{\circ} \mathrm{C}$ until use. Determination of the LHYal glycoside hydrolase activity was performed 
routinely by the 3,5-dinitrosalicylic acid colorimetric quantification of enzymatically released reducing sugars ${ }^{32}$.

Western Blot of type I hyaluronan synthase. C. glutamicum ATCC13032 expressing $\mathrm{C}$ terminally $6 \times$ histidine tagged spHasA, seHasA, suHasA, seHas ${ }^{\text {Thr7-Met } 25}$ were digested with $20 \mathrm{mg} \mathrm{mL}^{-1}$ lysozyme at room temperature for 2 hours and lysed with sonication in buffer containing $50 \mathrm{mM}$ Tris- $\mathrm{HCl}$, $5 \mathrm{mM}$ ethylenediaminetetraacetic acid and $1 \mathrm{mM}$ phenylmethanesulfonyl fluoride. Cell debris was removed by centrifugation at $16,099 \times g$ for 15 minutes. After BCA protein concentration assay, equal amount $(20 \mu \mathrm{g})$ of total protein samples were applied to SDS-PAGE. Afterwards, Western Blot was performed with 1:5000 diluted YTHXBio ZA004 His-tag mouse monoclonal antibody and 1:10000 diluted horseradish peroxidase labeled YTHXBio ZM03 goat antimouse IgG(H $+\mathrm{L})-\mathrm{HRP}$ ) (YTHX Biotechnology, Beijing, China).

Analysis of cell morphology by microscopy. For phase-contrast microscopy, cells were loaded on the thin layer of an agarose pad and visualized using an Eclipse NiE microscope (Nikon, Tokyo, Japan) equipped with a module for phase-contrast microscopy. To visualize cell encapsulation, cells were negatively stained with $100 \mathrm{mg} \mathrm{mL}^{-1}$ water-soluble nigrosin (Sangon Biotech, Shanghai, China), air dried and visualized with Eclipse Ni-E bright field microscope. Micrographs were processed with Image ${ }^{50}$.

Determination of HA effects on cell metabolism and growth. C. glutamicum ATCC 13032 was grown in glucose-corn steep powder medium for 10 hours, followed by centrifugation at $1789 \times g$ for 10 minutes and resuspension with fresh glucose-corn steep powder medium containing $20 \mathrm{~g} \mathrm{~L}^{-1}$ glucose and designated concentrations $\left(0,3,5\right.$, or $\left.10 \mathrm{~g} \mathrm{~L}^{-1}\right)$ of HA [obtained from Bloomage Biotechnology CO, LTD (Jinan, China) with purity higher than 98\%] or HA pretreated with $10,000 \mathrm{U} \mathrm{mL}^{-1} \mathrm{LHYal}$ at room temperature for 8 hours. The initial $\mathrm{OD}_{600}$ was set to 10 and cell growth and glucose consumption were measured every 2 hours.

Measurement HA weight average MW. Supernatant containing HA was isolated, as described above, using ice-cold ethanol precipitation. The crude HA samples were subjected to further purification with anion exchange chromatography via the ÄKTA avant 25 preparative chromatography system equipped with a HiPrep Q HP 16/10 (GE Healthcare, USA) column. Column was equilibrated with $50 \mathrm{mM}$ Tris$\mathrm{HCl}(\mathrm{pH}$ 8.0); fractions were gradient eluted with $0-200 \mathrm{mM} \mathrm{NaCl}$ and monitored with absorbance at wavelength of $210 \mathrm{~nm}$. Fractions were collected, freeze-dried, dissolved with appropriate amount of water and filtrated through a $0.22 \mu \mathrm{m}$ membrane. The weight average MW of HA was measured using high-performance size-exclusion chromatography (HPSEC) with multi-angle laser light scattering (MALLS) analysis. Briefly, $100 \mu \mathrm{L}$ of HA sample was injected into an HPSECMALLS system (equipped with Waters 515 HPLC pump, Shodex OHpak SB806HQ and Shodex OHpak SB-804HQ column series, DAWN HELEOS II MALLS instrument and Optilab dRI detector), fractions were separated in the column series with the mobile phase of $0.02 \%(\mathrm{~m} / \mathrm{v}) \mathrm{NaN}_{3}$ at $25^{\circ} \mathrm{C}$ at a flow rate of $1.0 \mathrm{~mL} \mathrm{~min}^{-1}$. The average value of two measurements was used to calculate the final weight average MW of HA.

Reporting summary. Further information on research design is available in the Nature Research Reporting Summary linked to this article.

\section{Data availability}

The authors declare that all data supporting the findings of this study are available within the paper and its supplementary information files. The datasets generated and analyzed during the current study are also available from the corresponding author upon request. The source data underlying Figures $1 b-e, 2 c-e, 3 a, 4 a, b, d, 5 a, b, 6 a-c$, and Tables 1 and 2 as well as Supplementary Figures $2 \mathrm{~b}, \mathrm{c}, 4 \mathrm{a}-\mathrm{c}, 6$ and Supplementary Table 1 are provided as a Source Data file. Source data are provided with this paper.

Received: 19 November 2019; Accepted: 1 June 2020;

Published online: 19 June 2020

\section{References}

1. Stecco, C. et al. Hyaluronan within fascia in the etiology of myofascial pain. Surg. Radio. Anat. 33, 891-896 (2011).

2. Averbeck, M. et al. Differential regulation of hyaluronan metabolism in the epidermal and dermal compartments of human skin by UVB irradiation. $J$. Invest. Dermatol. 127, 687-697 (2007).

3. Wessels, M. R., Moses, A. E., Goldberg, J. B. \& DiCesare, T. J. Hyaluronic acid capsule is a virulence factor for mucoid group A streptococci. Proc. Natl Acad. Sci. USA 88, 8317-8321 (1991).
4. Pandit, K. K. \& Smith, J. E. Capsular hyaluronic acid in Pasteurella multocida type A and its counterpart in type D. Res. Vet. Sci. 54, 20-24 (1993).

5. Xu, X., Jha, A. K., Harrington, D. A., Farach-Carson, M. C. \& Jia, X. Hyaluronic acid-based hydrogels: from a natural polysaccharide to complex networks. Soft Matter 8, 3280-3294 (2012).

6. Walimbe, T., Panitch, A. \& Sivasankar, P. M. A review of hyaluronic acid and hyaluronic acid-based hydrogels for vocal fold tissue engineering. J. Voice 31, 416-423 (2017).

7. Widjaja, L. K. et al. Hyaluronic acid-based nanocomposite hydrogels for ocular drug delivery applications. J. Biomed. Mater. Res. A 102, 3056-3065 (2014).

8. Kang, Z. et al. Bio-based strategies for producing glycosaminoglycans and their oligosaccharides. Trends Biotechnol. 36, 806-818 (2018).

9. Liu, L., Liu, Y., Li, J., Du, G. \& Chen, J. Microbial production of hyaluronic acid: current state, challenges, and perspectives. Microb. Cell Fact. 10, 99 (2011).

10. Mao, Z., Shin, H. D. \& Chen, R. A recombinant E. coli bioprocess for hyaluronan synthesis. Appl. Microbiol. Biotechnol. 84, 63-69 (2009).

11. Yu, H. \& Stephanopoulos, G. Metabolic engineering of Escherichia coli for biosynthesis of hyaluronic acid. Metab. Eng. 10, 24-32 (2008).

12. Westbrook, A. W., Ren, X., Moo-Young, M. \& Chou, C. P. Application of hydrocarbon and perfluorocarbon oxygen vectors to enhance heterologous production of hyaluronic acid in engineered Bacillus subtilis. Biotechnol. Bioeng. 115, 1239-1252 (2018).

13. Chien, L. J. \& Lee, C. K. Enhanced hyaluronic acid production in Bacillus subtilis by coexpressing bacterial hemoglobin. Biotechnol. Prog. 23, 1017-1022 (2007).

14. Jia, Y. et al. Metabolic engineering of Bacillus subtilis for the efficient biosynthesis of uniform hyaluronic acid with controlled molecular weights. Bioresour. Technol. 132, 427-431 (2013).

15. Jin, P., Kang, Z., Yuan, P., Du, G. \& Chen, J. Production of specific-molecularweight hyaluronan by metabolically engineered Bacillus subtilis 168. Metab. Eng. 35, 21-30 (2016).

16. Widner, B. et al. Hyaluronic acid production in Bacillus subtilis. Appl. Environ Microbiol. 71, 3747-3752 (2005).

17. Sunguroglu, C., Sezgin, D. E., Aytar Celik, P. \& Cabuk, A. Higher titer hyaluronic acid production in recombinant Lactococcus lactis. Prep. Biochem. Biotechnol. 48, 734-742 (2018).

18. Sheng, J., Ling, P. \& Wang, F. Constructing a recombinant hyaluronic acid biosynthesis operon and producing food-grade hyaluronic acid in Lactococcus lactis. J. Ind. Microbiol. Biotechnol. 42, 197-206 (2015).

19. Jeeva, P., Shanmuga Doss, S., Sundaram, V. \& Jayaraman, G. Production of controlled molecular weight hyaluronic acid by glucostat strategy using recombinant Lactococcus lactis cultures. Appl. Microbiol. Biotechnol. 103, 4363-4375 (2019).

20. Hmar, R. V., Prasad, S. B., Jayaraman, G. \& Ramachandran, K. B. Chromosomal integration of hyaluronic acid synthesis (has) genes enhances the molecular weight of hyaluronan produced in Lactococcus lactis. Biotechnol. J. 9, 1554-1564 (2014).

21. Hoffmann, J. \& Altenbuchner, J. Hyaluronic acid production with Corynebacterium glutamicum: effect of media composition on yield and molecular weight. J. Appl. Microbiol. 117, 663-678 (2014).

22. Cheng, F., Yu, H. \& Stephanopoulos, G. Engineering Corynebacterium glutamicum for high-titer biosynthesis of hyaluronic acid. Metab. Eng. 55, 276-289 (2019).

23. Jeong, E., Shim, W. Y. \& Kim, J. H. Metabolic engineering of Pichia pastoris for production of hyaluronic acid with high molecular weight. J. Biotechnol. 185, 28-36 (2014).

24. Mandawe, J. et al. Directed evolution of hyaluronic acid synthase from Pasteurella multocida towards high-molecular-weight hyaluronic acid. Chembiochem 19, 1414-1423 (2018)

25. Jing, W. \& DeAngelis, P. L. Synchronized chemoenzymatic synthesis of monodisperse hyaluronan polymers. J. Biol. Chem. 279, 42345-42349 (2004).

26. Schulte, S. et al. Exploiting the diversity of streptococcal hyaluronan synthases for the production of molecular weight-tailored hyaluronan. Appl. Microbiol. Biotechnol. 103, 7567-7581 (2019).

27. Baggenstoss, B. A. et al. Hyaluronan synthase control of synthesis rate and hyaluronan product size are independent functions differentially affected by mutations in a conserved tandem B-X7-B motif. Glycobiology 27, 154-164 (2017).

28. Westbrook, A. W., Ren, X., Moo-Young, M. \& Chou, C. P. Engineering of cell membrane to enhance heterologous production of hyaluronic acid in Bacillus subtilis. Biotechnol. Bioeng. 115, 216-231 (2018).

29. Cheng, F., Luozhong, S., Guo, Z., Yu, H. \& Stephanopoulos, G. Enhanced biosynthesis of hyaluronic acid using engineered Corynebacterium glutamicum via metabolic pathway regulation. Biotechnol. J. 12, 1700191 (2017). 
30. Kaur, M. \& Jayaraman, G. Hyaluronan production and molecular weight is enhanced in pathway-engineered strains of lactate dehydrogenase-deficient Lactococcus lactis. Metab. Eng. Commun. 3, 15-23 (2016).

31. Cheng, F., Gong, Q., Yu, H. \& Stephanopoulos, G. High-titer biosynthesis of hyaluronic acid by recombinant Corynebacterium glutamicum. Biotechnol. J. 11, 574-584 (2016).

32. Jin, P., Kang, Z., Zhang, N., Du, G. \& Chen, J. High-yield novel leech hyaluronidase to expedite the preparation of specific hyaluronan oligomers. Sci. Rep. https://doi.org/10.1038/srep04471 (2014).

33. Weigel, P. H. Hyaluronan synthase: the mechanism of initiation at the reducing end and a pendulum model for polysaccharide translocation to the cell exterior. Int. J. Cell Biol. 2015, 367579 (2015).

34. DeAngelis, P. L., Papaconstantinou, J. \& Weigel, P. H. Isolation of a Streptococcus pyogenes gene locus that directs hyaluronan biosynthesis in acapsular mutants and in heterologous bacteria. J. Biol. Chem. 268, 14568-14571 (1993).

35. Heldermon, C., DeAngelis, P. L. \& Weigel, P. H. Topological organization of the hyaluronan synthase from Streptococcus pyogenes. J. Biol. Chem. 276, 2037-2046 (2001).

36. DeAngelis, P. L., Jing, W., Drake, R. R. \& Achyuthan, A. M. Identification and molecular cloning of a unique hyaluronan synthase from Pasteurella multocida. J. Biol. Chem. 273, 8454-8458 (1998).

37. Donot, F., Fontana, A., Baccou, J. C. \& Schorr-Galindo, S. Microbial exopolysaccharides: main examples of synthesis, excretion, genetics and extraction. Carbohydr. Polym. 87, 951-962 (2012).

38. Puech, V. et al. Structure of the cell envelope of corynebacteria: importance of the non-covalently bound lipids in the formation of the cell wall permeability barrier and fracture plane. Microbiology 147, 1365-1382 (2001)

39. Jackson, M. The mycobacterial cell envelope-lipids. Cold Spring Harb. Perspect. Med. https://doi.org/10.1101/cshperspect.a021105 (2014).

40. Taniguchi, H. et al. Physiological roles of sigma factor SigD in Corynebacterium glutamicum. BMC Microbiol. 17, 158 (2017).

41. Islam, S. T. \& Lam, J. S. Synthesis of bacterial polysaccharides via the Wzx/Wzy-dependent pathway. Can. J. Microbiol. 60, 697-716 (2014).

42. Taubitz, I. S. \& Brandis, H. A comparison between methods of identification and serotyping of encapsulated strains of Haemophilus influenzae. Zentralblatt fur Bakteriologie, Mikrobiologie, und Hyg. 270, 83-97 (1988).

43. Yu, H., Tyo, K., Alper, H., Klein-Marcuschamer, D. \& Stephanopoulos, G. A high-throughput screen for hyaluronic acid accumulation in recombinant Escherichia coli transformed by libraries of engineered sigma factors. Biotechnol. Bioeng. 101, 788-796 (2008).

44. Zhang, L. et al. Rapid evolution of hyaluronan synthase to improve hyaluronan production and molecular mass in Bacillus subtilis. Biotechnol. Lett. 38, 2103-2108 (2016)

45. Tzeng, Y. L., Thomas, J. \& Stephens, D. S. Regulation of capsule in Neisseria meningitidis. Crit. Rev. Microbiol 42, 759-772 (2016).

46. Xia, Y. et al. T5 exonuclease-dependent assembly offers a low-cost method for efficient cloning and site-directed mutagenesis. Nucleic Acids Res. https://doi. org/10.1093/nar/gky1169 (2019).

47. Eggeling, L. \& Bott, M. Handbook of Corynebacterium glutamicum. (Taylor \& Francis, 2005).

48. Bitter, T. \& Muir, H. M. A modified uronic acid carbazole reaction. Anal. Biochem. 4, 330-334 (1962).
49. Wang, W. et al. Optimization of reactions between reducing sugars and 1phenyl-3-methyl-5-pyrazolone (PMP) by response surface methodology. Food Chem. 254, 158-164 (2018).

50. Schindelin, J. et al. Fiji: an open-source platform for biological-image analysis. Nat. Methods 9, 676-682 (2012).

\section{Acknowledgements}

This work was financially supported by the National Key R\&D program of China (2018YFA0901401), the National Natural Science Foundation of China (31970085), grant from the Key Technologies R\&D Program of Jiangsu Province (BE2019630), the Fundamental Research Funds for the Central Universities (JUSRP51707A), the Program for Changjiang Scholars and Innovative Research Team in University (IRT_15R26), and the 111 Project. Y.W. was sponsored by the China Postdoctoral Science Foundation (2019M651702).

\section{Author contributions}

Y.W. and L.H. performed the experiments. Z.K. and Y.W. designed the experiments. H.H. purified the leech hyaluronidase. H.W. contributed to the shake-flask cultivations. T.Z. contributed to the fed-batch cultivation. Z.K., Y.W., J.C. and G.D. drafted the manuscript.

\section{Competing interests}

The authors declare no competing interests.

\section{Additional information}

Supplementary information is available for this paper at https://doi.org/10.1038/s41467020-16962-7.

Correspondence and requests for materials should be addressed to Z.K.

Peer review information Nature Communications thanks Lothar Eggeling, and the other, anonymous, reviewer(s) for their contribution to the peer review of this work

Reprints and permission information is available at http://www.nature.com/reprints

Publisher's note Springer Nature remains neutral with regard to jurisdictional claims in published maps and institutional affiliations.

Open Access This article is licensed under a Creative Commons Attribution 4.0 International License, which permits use, sharing, adaptation, distribution and reproduction in any medium or format, as long as you give appropriate credit to the original author(s) and the source, provide a link to the Creative Commons license, and indicate if changes were made. The images or other third party material in this article are included in the article's Creative Commons license, unless indicated otherwise in a credit line to the material. If material is not included in the article's Creative Commons license and your intended use is not permitted by statutory regulation or exceeds the permitted use, you will need to obtain permission directly from the copyright holder. To view a copy of this license, visit http://creativecommons.org/ licenses/by/4.0/.

(C) The Author(s) 2020 